\title{
Influence of Pore Size on the Optical and Electrical Properties of Screen Printed $\mathrm{TiO}_{2}$ Thin Films
}

\author{
Dinfa Luka Domtau, ${ }^{1,2}$ Justus Simiyu, ${ }^{1}$ Elijah Omollo Ayieta, ${ }^{1}$ \\ Godwin Mwebeze Asiimwe, ${ }^{1}$ and Julius Mwakondo Mwabora ${ }^{1}$ \\ ${ }^{1}$ Department of Physics, University of Nairobi, Nairobi, Kenya \\ ${ }^{2}$ Department of Physics, University of Jos, Jos, Nigeria \\ Correspondence should be addressed to Dinfa Luka Domtau; domtaudinfa@gmail.com
}

Received 8 July 2016; Revised 24 August 2016; Accepted 5 September 2016

Academic Editor: Kaveh Edalati

Copyright (C) 2016 Dinfa Luka Domtau et al. This is an open access article distributed under the Creative Commons Attribution License, which permits unrestricted use, distribution, and reproduction in any medium, provided the original work is properly cited.

Influence of pore size on the optical and electrical properties of $\mathrm{TiO}_{2}$ thin films was studied. $\mathrm{TiO}_{2}$ thin films with different weight percentages (wt\%) of carbon black were deposited by screen printing method on fluorine doped tin oxide (FTO) coated on glass substrate. Carbon black decomposed on annealing and artificial pores were created in the films. All the films were $3.2 \mu \mathrm{m}$ thick as measured by a surface profiler. UV-VIS-NIR spectrophotometer was used to study transmittance and reflectance spectra of the films in the photon wavelength of 300-900 $\mathrm{nm}$ while absorbance was studied in the range of 350-900 nm. Band gaps and refractive index of the films were studied using the spectra. Reflectance, absorbance, and refractive index were found to increase with concentrations of carbon black. There was no significant variation in band gaps of films with change in carbon black concentrations. Transmittance reduced as the concentration of carbon black in $\mathrm{TiO}_{2}$ increased (i.e., increase in pore size). Currents and voltages $(I-V)$ characteristics of the films were measured by a 4-point probe. Resistivity $(\rho)$ and conductivity $(\sigma)$ of the films were computed from the $I-V$ values. It was observed that resistivity increased with carbon black concentrations while conductivity decreased as the pore size of the films increased.

\section{Introduction}

The interest of material scientists in titanium dioxide is on the increase due to its potentials in a wide range of industrial applications. $\mathrm{TiO}_{2}$ with a wide band gap of $3.2 \mathrm{eV}$ has attracted considerable interest because of the outstanding properties of its thin films such as electrical, optical, and chemical properties. These properties include high conductivity, high refractive index, and high transparency in the visible region. Thus $\mathrm{TiO}_{2}$ is useful in applications such as photocatalyst [1], dye sensitized solar cells [2], chemical sensors [3-5], electrochromics [6], and electronic devices [7].

The quality of the $\mathrm{TiO}_{2}$ film is influenced by the type of material and method used for film deposition and subsequent sintering procedure. The properties of the films such as surface area, roughness, and pore size and film thickness are responsible for its surface and electronic properties. Cho et al. presented a simple architecture that achieves enhanced light scattering in $\mathrm{TiO}_{2}$ films [8]. Polystyrene (PS) spheres of submicrometer size were incorporated into the $\mathrm{TiO}_{2}$ paste resulting in photoanode with bimodal pore size distribution. The optical properties of the films were improved by the enhancement of the films' pore size. Furthermore, $\mathrm{TiO}_{2}$ films with artificial pores formed using acetylene black to improve the light scattering films without a light scattering layer have also been fabricated [9]. The artificial films were found to improve the reflectance of the films. The dependence of optical properties of $\mathrm{TiO}_{2}$ thin films has been reported to depend on pore size $[10,11]$. Refractive index and electrical resistivity were found to depend on porosity of the films and bandgap was found to depend on annealing temperature and grain size. However, the effect of pore size on the optical and electrical properties of $\mathrm{TiO}_{2}$ thin films especially for optimum applications in dye sensitized solar cells has not 
been adequately explored. It has been reported that the substrate temperature [12-14], deposition rate $[15,16]$, and film thickness have important effects on the morphology and nanostructure of thin films. $\mathrm{TiO}_{2}$ thin films have been deposited by various techniques; these include tape casting [17], screen printing [18-20], and electrophoretic deposition [21]. Of all the aforementioned, screen printing technique is simple, of low cost, and easily reproducible.

In this work, we created some size-varying artificial pores in $\mathrm{TiO}_{2}$ thin films. This work seeks to provide information on the optical and electrical properties of pore size enhanced $\mathrm{TiO}_{2}$ films that may find optimum applications in dye sensitized solar cells. We simply mixed carbon black powder with $\mathrm{TiO}_{2}$ paste and deposited onto glass by screen printing method. The carbon black simply decomposed on annealing leaving behind voids in the films.

\section{Experimental Details}

The $\mathrm{TiO}_{2}$ thin films were prepared using screen printing method as follows: commercially available $\mathrm{TiO}_{2}$ paste purchased from Solaronix (Ti-Nanoxide T/SP) was used as original and control paste, into which varying weight percentages of carbon black would be added. $\mathrm{TiO}_{2}$ anatase concentration is $18 \mathrm{wt} \%$; particle size is of $18-20 \mathrm{~nm}$ and transparent. The carbon black powder was purchased from Alfa Aesar (acetylene, 100\% compressed). $2 \mathrm{~mm}$ thick glass substrates with $15 \Omega$ /sq. fluorine doped tin oxide (FTO) coating on one side purchased from Solaronix were ultrasonically cleaned in distilled water for 20 minutes, dipped in acetone for 20 minutes, and finally rinsed in distilled water.

Ti-Nanoxide T/SP was diluted in absolute ethanol and mixed with a magnetic stirrer bar for 30 minutes. Different weight percentages $(0.5,1,1.5,2$, and $3 \mathrm{wt} \%)$ were added to the suspension. The suspension was dispersed with a sonication horn (digital Sonifier 450) to break any aggregates of nanoparticles. It was sonicated in pulses ( $2 \mathrm{~s} \mathrm{ON}, 2 \mathrm{~s} \mathrm{OFF}$ ) to avoid temperature elevation for 30 minutes in intervals of 6 minutes and stirred for 5 minutes at each interval. The mixture was then transferred to a rotary evaporator at $80^{\circ} \mathrm{C}$, $100 \mathrm{mbar}$. The paste was again homogenized by a grinder after the ethanol was evaporated. The mixture of $\mathrm{TiO}_{2}$ paste and carbon black of different weight percentages of carbon black was coated (by screen printing method) one time each onto FTO/glass using a $63 \mathrm{~T}$ mesh. All the films were sintered in tube furnace at $500^{\circ} \mathrm{C}$ for 30 minutes in air. At this temperature, carbon black was completely burnt out leaving behind voids in the films.

The surface microstructural features of the films were characterized using Multimode 8-HR Atomic Force Microscopy/Scanning Tunneling Microscopy (AFM/STM) in taping mode. Optical transmittance, reflectance, and absorbance spectra of $\mathrm{TiO}_{2}$ thin films were studied using Shimadzu UV-VIS-NIR Spectrophotometer (SolidSpec3700/3700DUV, Japan, Inc.) Film thickness was measured by a surface profiler (alpha-step IQ). Sheet resistances of the films were measured by Jandel RM3-AR 4-Point Probe.

\section{Results and Discussions}

The $\mathrm{TiO}_{2}$ thin films prepared were incorporated with $0,0.5$, $1,1.5,2$, and $3 \mathrm{wt} \%$ of carbon black. All the films were $3.2 \mu \mathrm{m}$ of thickness to restrict the influence of film thickness on the samples. Figures 1(a), 1(b), 1(c), 1(d), 1(e), and 1(f) show the dependence of pore size on carbon black concentrations. Figures 1(a), 1(b), 1(c), 1(d), 1(e), and 1(f) were incorporated with $0,0.5,1,1.5,2$, and $3 \mathrm{wt} \%$ of carbon black. It was observed that the higher the wt\% of carbon black incorporated into the $\mathrm{TiO}_{2}$ films the larger the sizes of voids left behind after the combustion of the carbon black. We also found that, beyond $3 \mathrm{wt} \%$, carbon black does not burn out at the annealing temperature of $500^{\circ} \mathrm{C}$. That is to say with any further addition of carbon with annealing temperature remaining the same, $\mathrm{TiO}_{2}$ films will be contaminated; thus purity will be compromised.

Transmittance spectra of the films are as shown in Figure $2.0 \mathrm{wt} \% \mathrm{TiO}_{2}$ thin film showed high transparency in the visible region and decreased sharply at the UV region but dropped steadily towards the NIR. The transmittance spectra have the highest value of $79 \%$. It was observed that as the weight percentage of carbon black increased (i.e., as the pore size increased), the transmittance decreased. The film with the highest weight percentage of carbon black was the least transparent (39\%). We observed that transmittance spectra in samples $2 \mathrm{wt} \%$ and $3 \mathrm{wt} \%$ dropped drastically as compared to other samples. Though the pore size in these samples also increased which resulted in drop in transmittance, the drastic drop could be due to residue of carbon black left behind. At such concentrations, $500^{\circ} \mathrm{C}$ is not sufficient to completely burn out carbon black; hence residue is responsible for light blockage.

Figure 3 shows the reflectance spectra of $\mathrm{TiO}_{2}$ thin films with different weight percentages of carbon black. It was observed that reflectance increased with pore size. The increase in reflectance is a result of multiple light scattering by the pores created [9]. Otherwise, it also accounts for the decrease in the films transmittance as the pores increased.

Figure 4 shows absorbance spectra of $\mathrm{TiO}_{2}$ thin films with varying weight percentages of carbon black. The absorption edge of $\mathrm{TiO}_{2}$ as seen in Figure 3 is $300 \mathrm{~nm}$. The step observed at $720 \mathrm{~nm}$ is a result of the change in detectors of the spectrophotometer. As the pores increased, absorbance increased due to increase in optical path length, optical light confinement, or light trapping [9]. The $0 \mathrm{wt} \% \mathrm{TiO}_{2}$ thin film has the least absorbance and film with the highest carbon black concentration has the highest absorbance. Our observations are in agreement with some previous investigations $[8,9]$.

From interband absorption theory, the optical band gap of $\mathrm{TiO}_{2}$ films can be determined from the formula [22]

$$
(\alpha h \nu)^{m}=A\left(h \nu-E_{g}\right),
$$

where $\alpha$ is the absorption coefficient, $A$ is a constant, $h \nu$ is photon energy $(\mathrm{eV})$, and $m$ is the transition coefficient. $m=1 / 2$ and $3 / 2$ corresponds to direct allowed and direct forbidden transitions and $m=2,3$ corresponds to indirect 

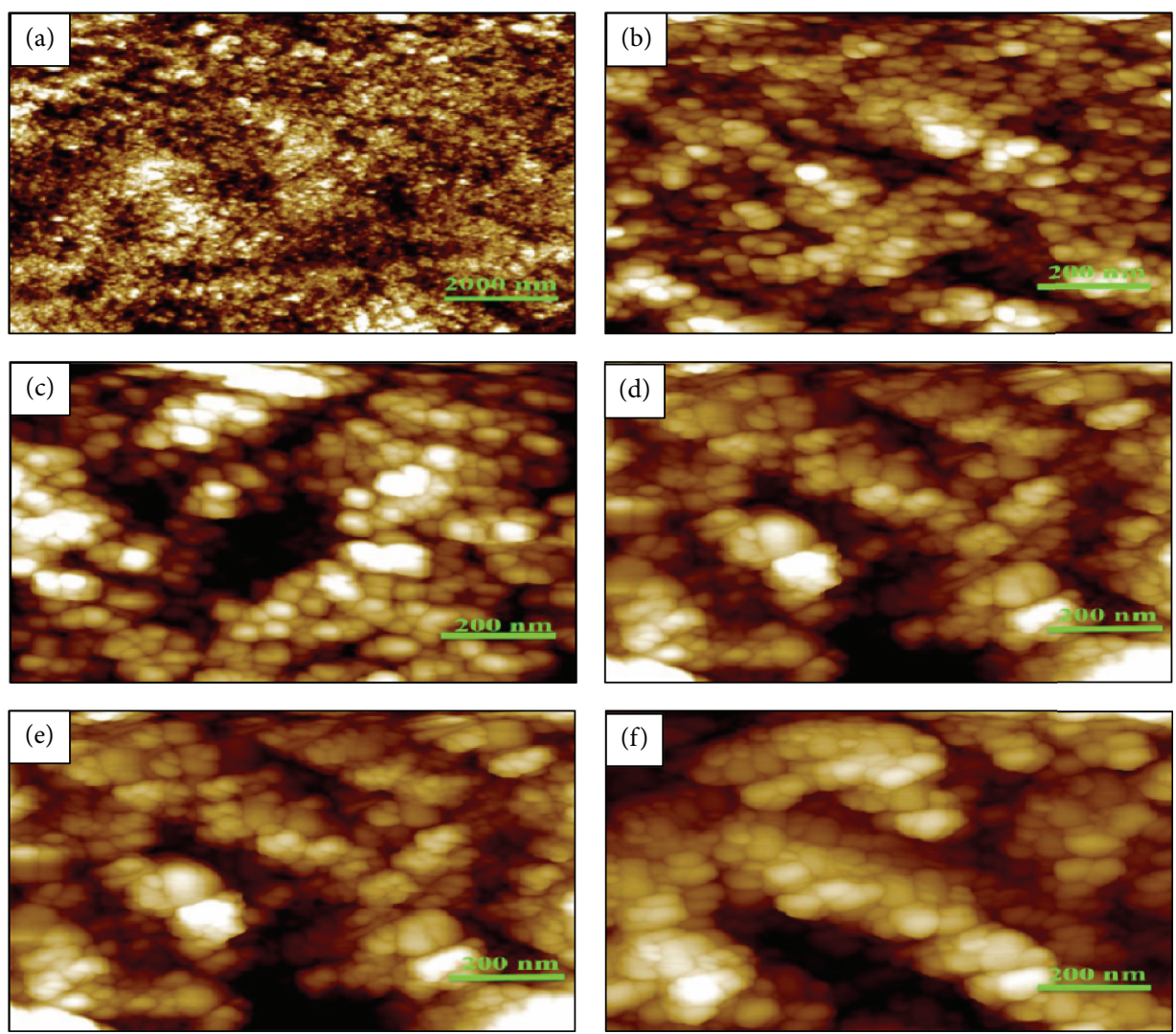

FIGURE 1: AFM/STM images of $\mathrm{TiO}_{2}$ film with different wt $\%$ of carbon black.

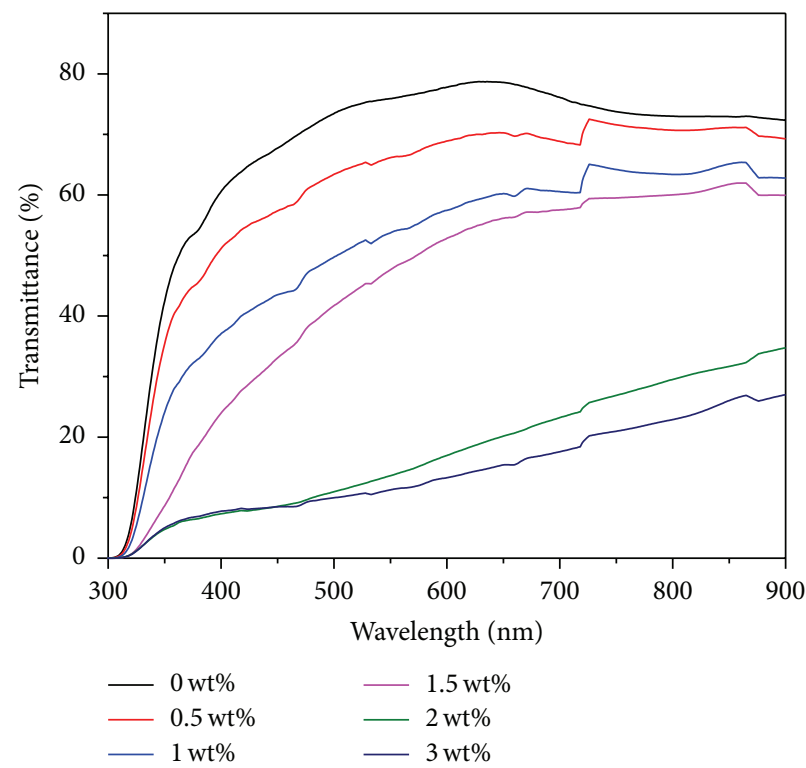

FIgURE 2: Transmittance spectra of $\mathrm{TiO}_{2}$ thin films with different wt $\%$ of carbon black.

allowed and indirect forbidden transitions, respectively [22]. The absorption coefficient is thus calculated from the relation

$$
\alpha=\frac{1}{d} \ln \left(\frac{1}{T}\right)
$$

where $d$ is the film thickness and $T$ the transmittance of the film at each wavelength.

The optical band gaps were obtained from plotting Tauc's equation using $1 / 2$ for $m$ and extrapolating the straight line part of the curve to $(\alpha h v)^{1 / m}=0$. It was observed that for all 


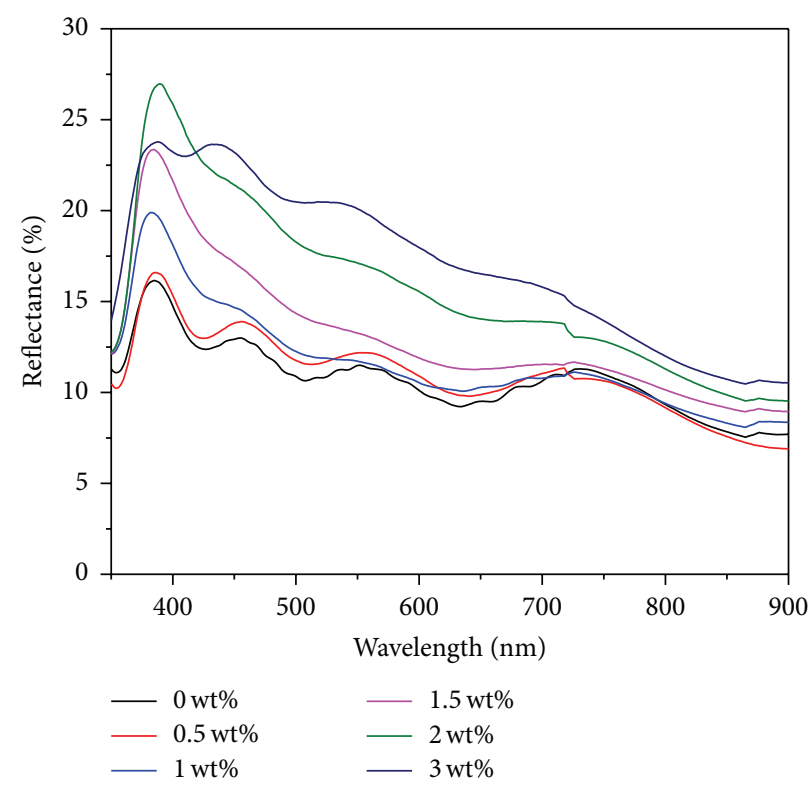

FIgURE 3: Reflectance spectra of $\mathrm{TiO}_{2}$ thin films with varying wt $\%$ of carbon black.

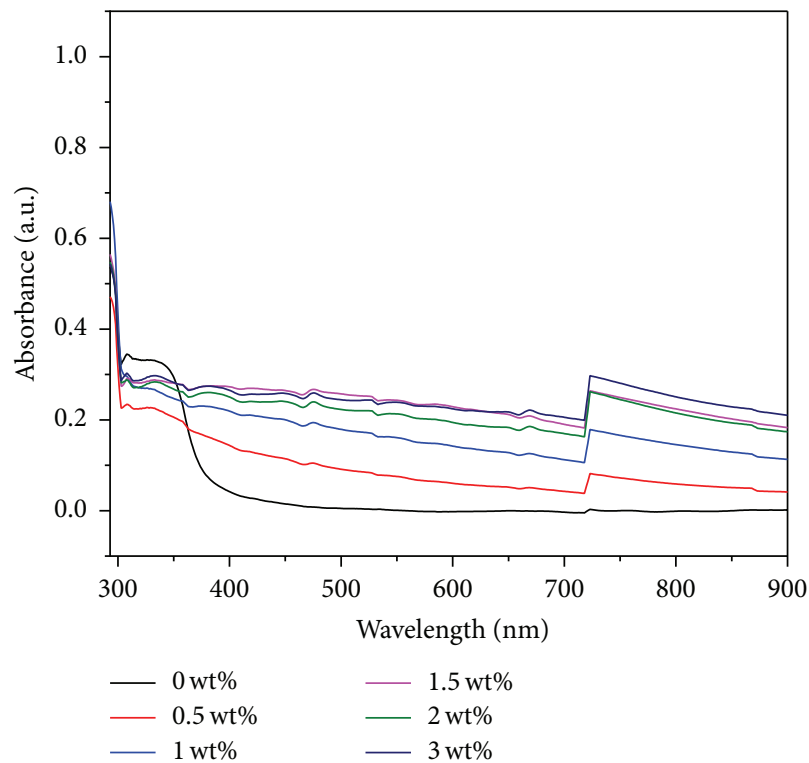

Figure 4: Absorbance of $\mathrm{TiO}_{2}$ thin films with different wt $\%$ of carbon black.

the films, the best straight line is obtained for the value of $m$ equal to $1 / 2$, which is typical of direct allowed transitions [22].

Figure 5 shows the band gaps of $\mathrm{TiO}_{2}$ thin films with different weight percentages of carbon. We observed that pore size had no effect on band gaps as all the films despite their variations in pore size have a band gap of $\approx 3.8 \mathrm{eV}$.

The refractive index was computed using the relation [23]

$$
n=\frac{1+R}{1-R}+\left[\frac{4 R}{(1-R)^{2}}-K^{2}\right]^{1 / 2}
$$

where $n$ is refractive index, $R$ is reflectance, $\lambda$ is wavelength, and $K$ is the extinction coefficient given as

$$
K=\frac{\alpha \lambda}{4 \pi} \text {. }
$$

The refractive indices of $\mathrm{TiO}_{2}$ thin films of different wt $\%$ were obtained from (3) and plotted in Figure 6.

Figure 6 shows that refractive index increased with increase in pore size. $0 \mathrm{wt} \% \mathrm{TiO}_{2}$ film has the least refractive index within the visible range. Any other film with artificial pores has refractive index higher than the $0 \mathrm{wt} \%$ film and 

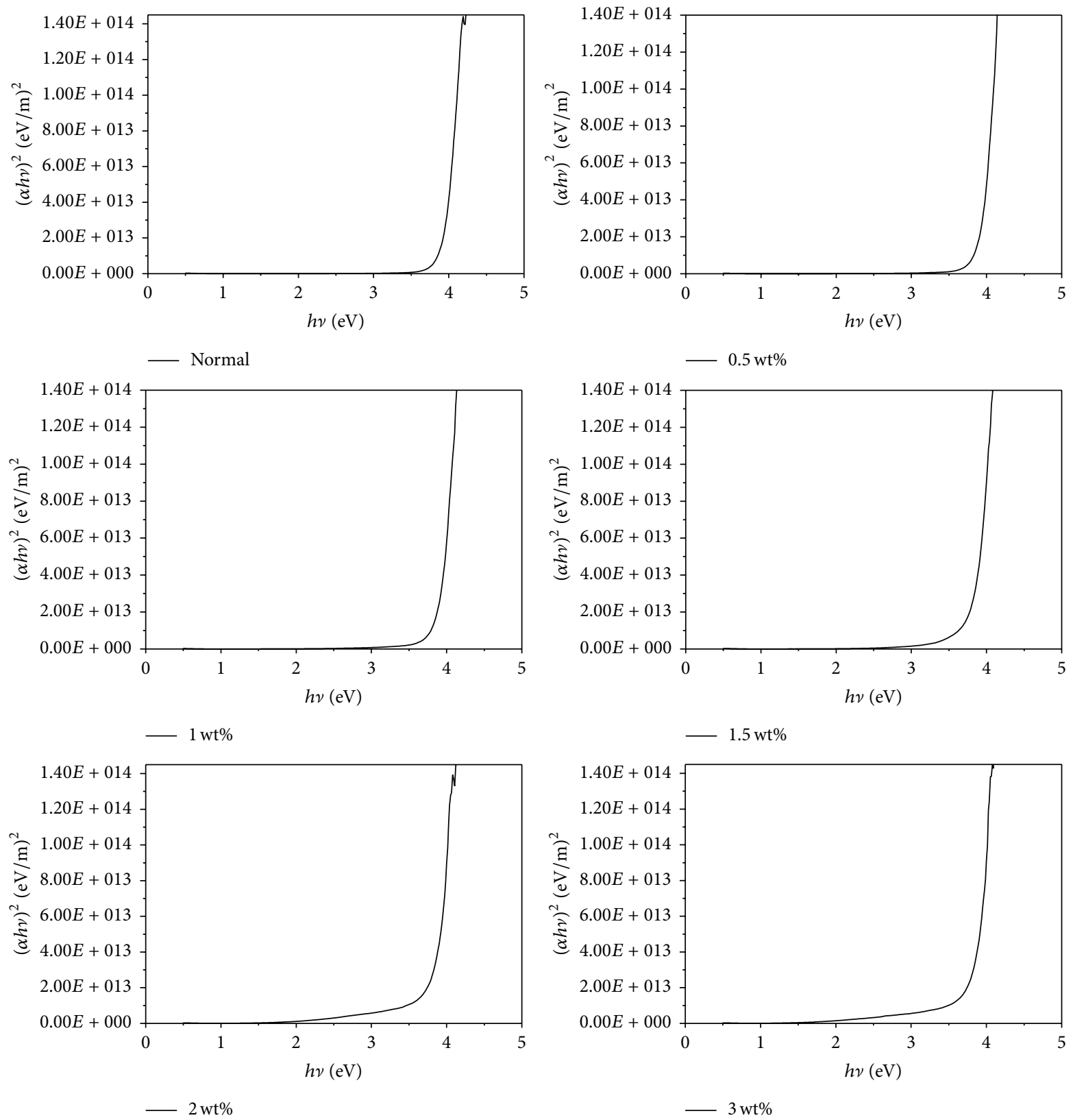

Figure 5: Band gap of $\mathrm{TiO}_{2}$ thin films with different wt $\%$ of carbon black.

that was how refractive index kept rising with increase in pore size. This is due to the fact that the increase in pore size increases light scattering and delay in light path or light trapping [9]. Refractive index increased from 1.4 (0 wt $\%$ $\left.\mathrm{TiO}_{2}\right)$ to $1.8(2 \mathrm{wt} \%)$ as the pore size increased. It shows that pore size truly has influence on the refractive index of $\mathrm{TiO}_{2}$.

From the measured $I-V$ by a 4 -point probe, electrical resistivity was calculated using the following equation since they are thin film samples:

$$
\rho=\frac{\pi}{\ln 2} \frac{v}{I} \times \text { thickness, }
$$

where $\rho$ is resistivity, $v$ is voltage, $I$ is current, and $\pi / \ln 2=$ 4.53 .
TABLE 1: Resistivity and conductivity of $\mathrm{TiO}_{2}$ thin films with varying wt $\%$ of carbon black.

\begin{tabular}{lcc}
\hline $\begin{array}{l}\text { Weight } \\
\text { ratio }(\%)\end{array}$ & Resistivity $(\Omega \cdot \mathrm{cm})$ & Conductivity $\left(\right.$ Siemen's $\left.\cdot \mathrm{cm}^{-1}\right)$ \\
\hline 0.5 & $2.60 \times 10^{-3}$ & 384.61 \\
1.0 & $2.84 \times 10^{-3}$ & 352.11 \\
1.5 & $9.67 \times 10^{-3}$ & 103.41 \\
2.0 & $19.08 \times 10^{-3}$ & 52.41 \\
3.0 & $28.33 \times 10^{-3}$ & 35.29 \\
\hline
\end{tabular}

The results are tabulated in Table 1 . 


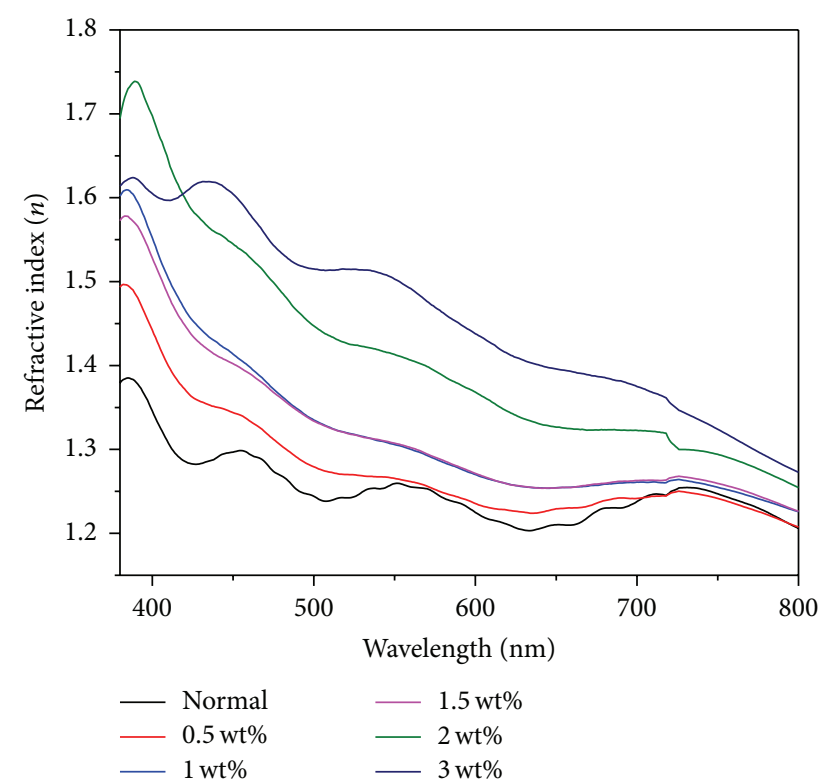

FIgure 6: Refractive index of $\mathrm{TiO}_{2}$ thin films with different wt $\%$ of carbon black.

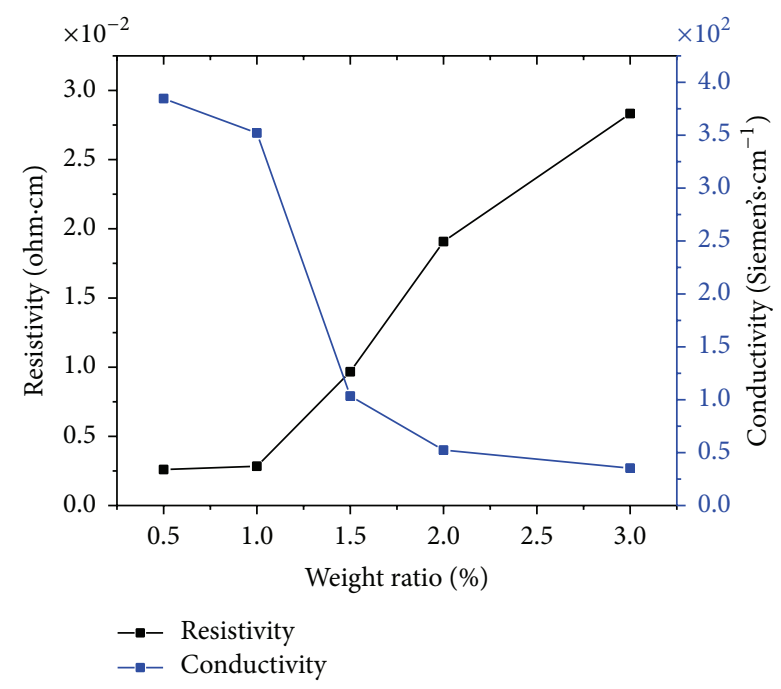

FIGURE 7: Resistivity and conductivity of $\mathrm{TiO}_{2}$ thin films with different wt\% of carbon black.

We found that resistivity decreased with increase in weight concentrations of carbon black.

Conductivity of $\mathrm{TiO}_{2}$ thin films is the inverse of resistivity. Resistivity and conductivity are given by the relation

$$
\sigma=\frac{1}{\rho},
$$

where $\sigma$ is conductivity. The values for conductivity are also tabulated in Table 1 . Figure 7 shows the resistivity and conductivity of $\mathrm{TiO}_{2}$ thin films with different wt $\%$ of carbon black.

It was observed that conductivity decreased with increase in concentrations of carbon black. This is because the increase in pore size reduces the electronic contact between $\mathrm{TiO}_{2}$ particles. So, also as the electronic contacts between the molecules reduce, resistivity increases; hence the observation is shown in Figure 7. Resistivity increased from $2.6 \times$ $10^{-3} \Omega \cdot \mathrm{cm}$ to $28.3 \times 10^{-3} \Omega \cdot \mathrm{cm}$ while conductivity decreased from 384.61 Siemen's $\cdot \mathrm{cm}^{-1}$ to 35.29 Siemen's $\cdot \mathrm{cm}^{-1}$ as the pore size increased.

\section{Conclusion}

Titanium oxide thin films of $3.2 \mu \mathrm{m}$ thickness (with and without) different wt $\%$ of carbon black were deposited on FTO/glass and then subjected to an annealing temperature of $500^{\circ} \mathrm{C}$ for 30 minutes. Carbon black was completely burnt out at this temperature and artificial pores were created. Pore size effect on the optical and electrical properties of the films were investigated. UV-VIS studies revealed that normal $\mathrm{TiO}_{2}$ thin film is highly transparent in the visible region with a value of $79 \%$. Transmittance decreased with increase in pore size while reflectance and absorbance increased as the pore size becomes larger. Refractive indices of the films also increased with increase in pore size of the films. However the band gap as calculated from the transmittance spectra remained constant with change in films' pore size. We also found that resistivity rose from 2.6 $\times 10^{-3} \Omega \cdot \mathrm{cm}$ to $28.3 \times 10^{-10} \Omega \cdot \mathrm{cm}$ and conductivity dropped from 384.61 Siemen's $\mathrm{cm}^{-1}$ to 35.29 Siemen's $\cdot \mathrm{cm}^{-1}$ as pore size increased. These films will find useful applications in dye sensitized solar cells because of their increased light scattering ability and their high transmittance in the visible region. The high refractive index in the visible region is also important in solar cell applications. Pores created will also serve as good anchoring sites for dye molecules, thereby enhancing higher photocurrent generation. The relatively high conductivity of these films will also make them suitable for solar cells applications.

\section{Competing Interests}

The authors declare that they have no competing interests.

\section{References}

[1] A. L. Linsebigler, G. Lu, and J. T. Yates Jr., "Photocatalysis on $\mathrm{TiO}_{2}$ surfaces: principles, mechanisms, and selected results," Chemical Reviews, vol. 95, no. 3, pp. 735-758, 1995.

[2] U. Bach, D. Lupo, P. Comte et al., "Solid-state dye-sensitized mesoporous $\mathrm{TiO}_{2}$ solar cells with high photon-to-electron conversion efficiencies," Nature, vol. 395, no. 6702, pp. 583-585, 1998.

[3] L. R. Skubal, N. K. Meshkov, and M. C. Vogt, "Detection and identification of gaseous organics using a $\mathrm{TiO}_{2}$ sensor," Journal of Photochemistry and Photobiology A: Chemistry, vol. 148, no. 1-3, pp. 103-108, 2002.

[4] S.-A. Gao, A.-P. Xian, L.-H. Cao, R.-C. Xie, and J.-K. Shang, "Influence of calcining temperature on photoresponse of $\mathrm{TiO}_{2}$ film under nitrogen and oxygen in room temperature," Sensors and Actuators B: Chemical, vol. 134, no. 2, pp. 718-726, 2008. 
[5] D. Mardare, N. Iftimie, and D. Luca, " $\mathrm{TiO}_{2}$ thin films as sensing gas materials," Journal of Non-Crystalline Solids, vol. 354, no. 3539, pp. 4396-4400, 2008.

[6] N. N. Dinh, N. Th. T. Oanh, P. D. Long, M. C. Bernard, and A. Hugot-Le Goff, "Electrochromic properties of $\mathrm{TiO}_{2}$ anatase thin films prepared by a dipping sol-gel method," Thin Solid Films, vol. 423, no. 1, pp. 70-76, 2003.

[7] N. Zhong, H. Shima, and H. Akinaga, "Mechanisms of the performance improvement of $\mathrm{TiO}_{2-x}$ based field-effect transistor using $\mathrm{SiO}_{2}$ as gate insulator," AIP Advances, vol. 1, Article ID 032167, 8 pages, 2011.

[8] T.-Y. Cho, C.-W. Han, Y. Jun, and S.-G. Yoon, "Formation of artificial pores in nano- $\mathrm{TiO}_{2}$ photo-electrode films using acetyleneblack for high-efficiency, dye-sensitized solar cells," Scientific Reports, vol. 3, article 1496, 2013.

[9] T. Pham, T. Bessho, N. Mathews et al., "Light scattering enhancement from sub-micrometer cavities in the photoanode for dye-sensitized solar cells," Journal of Materials Chemistry, vol. 22, no. 32, pp. 16201-16204, 2012.

[10] M. Bartic, L. Sacarescu, and V. Harabagiu, "Optical and electrical properties of $\mathrm{TiO}_{2}$ thin films deposited by sol-gel method," Revue Roumaine de Chimie, vol. 58, no. 2-3, pp. 105-111, 2013.

[11] F. Hanini, A. Bouabellou, Y. Bouachiba et al., "Structural, optical and electrical properties of $\mathrm{TiO}_{2}$ thin films synthesized by solgel technique," Journal of Engineering, vol. 3, no. 11, pp. 21-28, 2013.

[12] T. Ida and H. Toraya, "Deconvolution of the instrumental functions in powder X-ray diffractometry," Journal of Applied Crystallography, vol. 35, no. 1, pp. 58-68, 2002.

[13] M. Cernanský, "Some practical aspects of the Fourier deconvolution," Journal of Applied Crystallography, vol. 16, pp. 103-112, 1983.

[14] R. W. Cheary and A. Coelho, "Thin film analysis by X-ray scattering," Journal of Applied Crystallography, vol. 25, pp. 109121, 1992.

[15] S. A. Howard and R. L. Snyder, "X-ray characterization of materials," Journal of Applied Crystallography, vol. 22, pp. 238243, 1989.

[16] S. Enzo, G. Fagherazzi, A. Benedetti, and S. Polizzi, "A profilefitting procedure for analysis of broadened X-ray diffraction peaks. I. methodology," Journal of Applied Crystallography, vol. 21, no. 5, pp. 536-542, 1988.

[17] M. K. Nazeeruddin, A. Kay, I. Rodicio et al., "Conversion of light to electricity by cis-X2bis $\left(2,2^{\prime}\right.$-bipyridyl- $4,4^{\prime}$-dicarboxylate)ruthenium(II) charge-transfer sensitizers (X=Cl-, Br-, I-, CN-, and SCN-) on nanocrystalline titanium dioxide electrodes," Journal of the American Chemical Society, vol. 115, no. 14, pp. 6382-6390, 1993.

[18] D. S. Tsoukleris and I. M. Arabatzis, "Environmental applications of solar energy," Solar Energy, vol. 79, pp. 422-430, 2005.

[19] L. Ma, M. Liu, T. Peng, K. Fan, L. Lu, and K. Dai, "Fabrication and properties of meso-macroporous electrodes screen-printed from mesoporous titania nanoparticles for dye-sensitized solar cells," Materials Chemistry and Physics, vol. 118, pp. 477-483, 2009.

[20] K. Fan, M. Liu, T. Peng, L. Ma, and K. Dai, "Effects of paste components on the properties of screen-printed porous $\mathrm{TiO}_{2}$ film for dye-sensitized solar cells," Renewable Energy, vol. 35, no. 2, pp. 555-561, 2010.

[21] T. Miyasaka, Y. Kijitori, T. N. Murakami, M. Kimura, and S. Uegusa, "Efficient nonsintering type dye-sensitized photocells based on electrophoretically deposited $\mathrm{TiO}_{2}$ layers," Chemistry Letters, vol. 31, no. 12, pp. 1250-1251, 2002.

[22] C. Kittel, Introduction to Solid State Physics, John Wiley and Sons, New York, NY, USA, 7th edition, 1996.

[23] Q. Y. Cai, Y. Zheng, P. Mao et al., "Evolution of optical constants of silicon dioxide on silicon from ultrathin films to thick films," Journal of Physics D: Applied Physics, vol. 43, no. 44, Article ID 445302, 2010. 

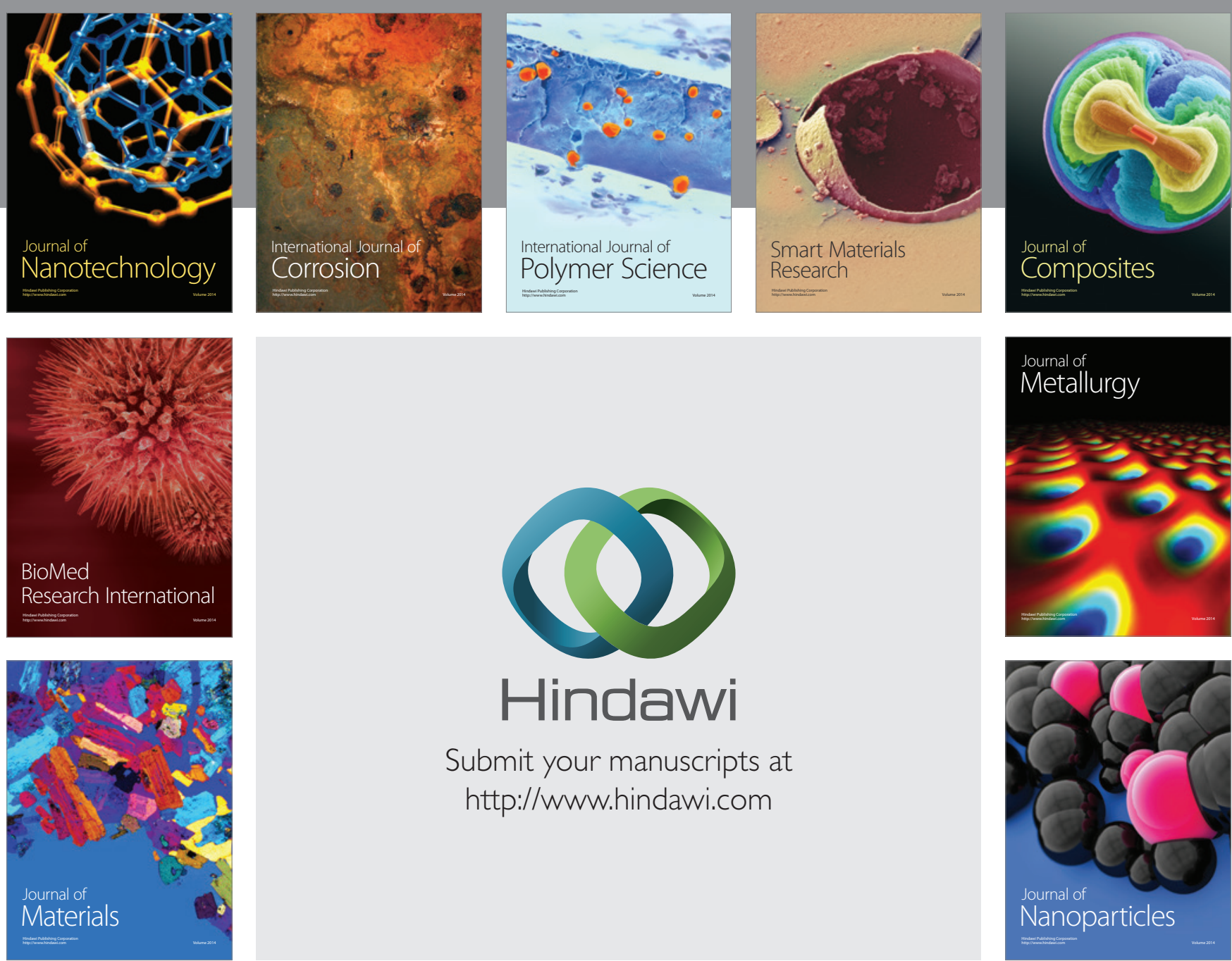

\section{Hindawi}

Submit your manuscripts at

http://www.hindawi.com

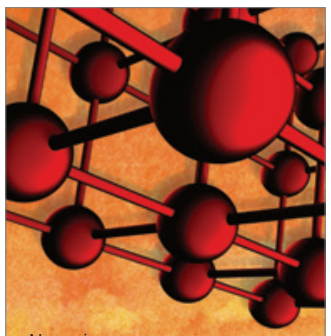

Materials Science and Engineering
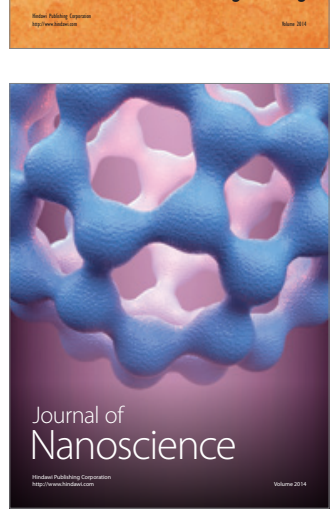
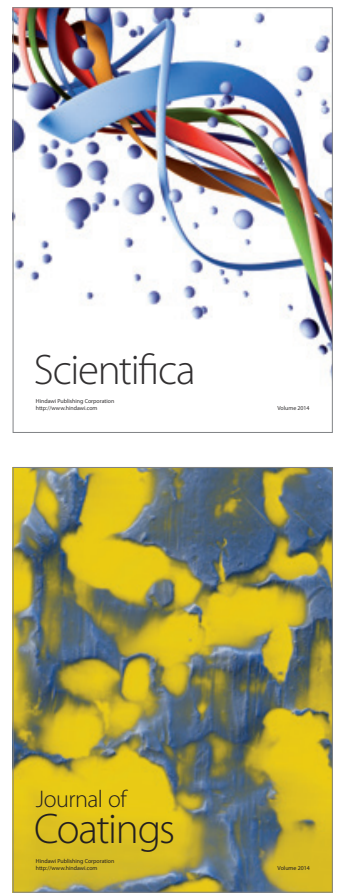
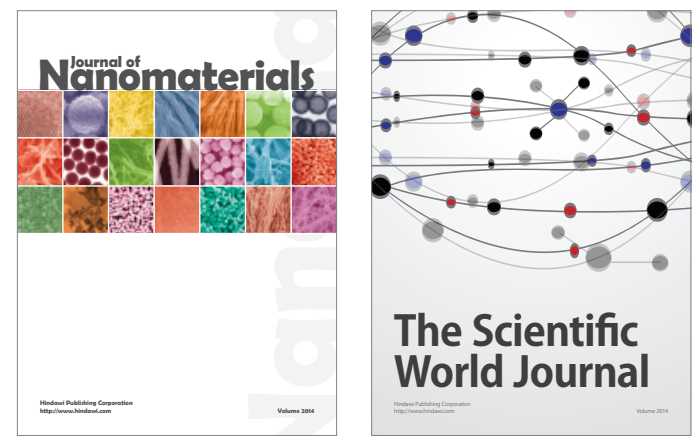

The Scientific World Journal
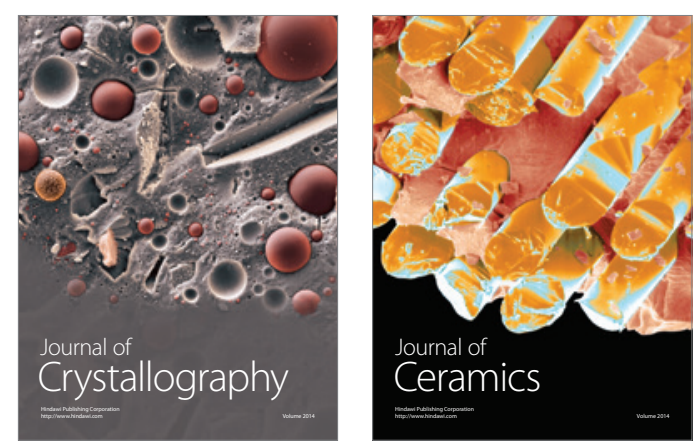
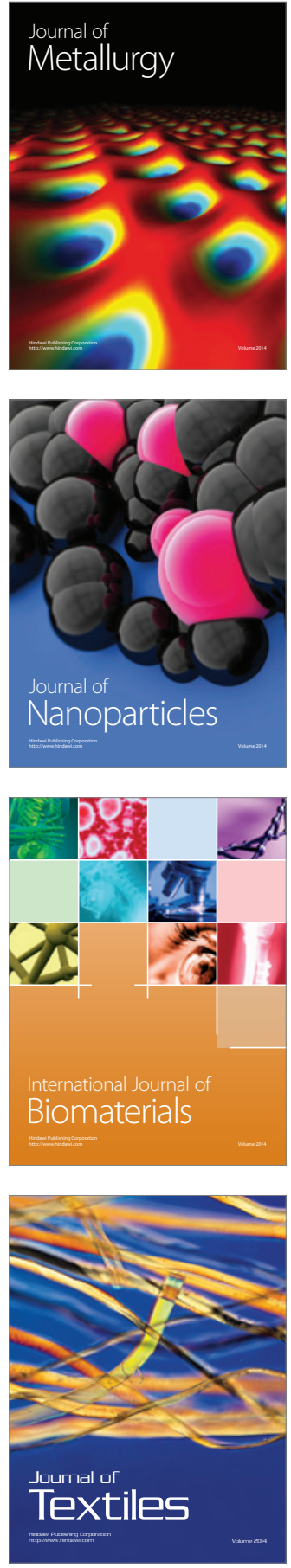